This document is confidential and is proprietary to the American Chemical Society and its authors. Do not copy or disclose without written permission. If you have received this item in error, notify the sender and delete all copies.

\title{
Transport of $\mathbf{N}$-nitrosamines through reverse osmosis membrane: Role of the molecular size and nitrogen atom
}

\begin{tabular}{|r|l|}
\hline Journal: & Environmental Science \& Technology Letters \\
\hline Manuscript ID & ez-2018-00624r.R1 \\
\hline Manuscript Type: & Letter \\
\hline Dute Submitted by the & $\mathrm{n} / \mathrm{a}$ \\
\hline Complete List of Authors: & $\begin{array}{l}\text { Fujioka, Takahiro; Nagasaki Daigaku, Graduate School of Engineering } \\
\text { Kodamatani, Hitoshi; Kagoshima University, Faculty of Science } \\
\text { Nghiem, Long; University of Technology Sydney } \\
\text { SHINTANI, Takuji ; Kobe University }\end{array}$ \\
\hline
\end{tabular}

\section{SCHOLARONE Manuscripts}


1 Transport of $\boldsymbol{N}$-nitrosamines through Reverse Osmosis Membrane: Role of the Molecular Size and Nitrogen Atom Takahiro Fujioka, †,* Hitoshi Kodamatani, ${ }^{\ddagger}$ Long D. Nghiem, ${ }^{\S}$ Takuji Shintani" $\dagger$ Water and Environmental Engineering, Graduate School of Engineering, Nagasaki University, 1-14 Bunkyo-machi, Nagasaki 852-8521, Japan

6 Division of Earth and Environmental Science, Graduate School of Science and Engineering, Kagoshima University, 1-21-35 Korimoto, Kagoshima 890-0065, Japan ${ }^{\S}$ Centre for Technology in Water and Wastewater, University of Technology Sydney, Ultimo NSW 2007, Australia 'Division of Advanced Membrane Science and Technology, Graduate School of Science, 11 Technology and Innovation, Kobe University, 1-1 Rokkodai-cho, Kobe 657-8501, Japan 


\section{Abstract}

16 Reliable and adequate removal of small and uncharged trace organic chemicals (TOrCs),

17 particularly $N$-nitrosodimethylamine (NDMA) that is carcinogenic and known to occur in treated

18 effluent, is essential for implementing direct potable water use. This study provides new insights

19 to explain the low rejection of NDMA and other $N$-nitrosamines by reverse osmosis (RO)

20 membranes by examining the role of the molecular size and polarity in their molecular structure.

21 The results show that molecular weight is not a suitable molecular property for evaluating the

22 rejection of small uncharged chemicals. In this study, NDMA and two other uncharged

23 chemicals have similar MW (i.e., $72-74 \mathrm{~g} / \mathrm{mol}$ ), but their rejection by the ESPA2 RO membrane

24 varied considerably from 30 to $88 \%$. Instead, minimum projection area was identified to be a

25 suitable molecular property, indicating that size exclusion plays a primary role in their rejection.

26 It was also identified that chemicals with more nitrogen atoms in their chemical structure

27 consistently showed lower rejection than their counterparts in molecular size. The results suggest

28 that chemicals bearing more nitrogen atoms (e.g., NDMA) are more attracted onto amide or

29 amine functional group of polyamide RO membrane possibly through hydrogen bonding

30 interactions.

31 Keywords: $N$-nitrosodimethylamine; $N$-nitrosamine; potable reuse; polarity; reverse osmosis. 


\section{INTRODUCTION}

$34 N$-nitrosamines are a group of trace organic chemical (TOrC) of significant concern in potable

35 reuse. Notable chemicals in this group include $N$-nitrosodimethylamine (NDMA), $N$ -

36 nitrosomethylethylamine (NMEA), $N$-nitrosopyrrolidine (NPYR), and $N$-nitrosomorpholine

37 (NMOR). They are probable carcinogenic and are known to occur in secondary treated effluent

38 after chloramination. ${ }^{1-3}$ Several water authorities around the world have issued standards or

39 guidelines to regulate their maximum concentration in water for potable reuse. For example, the

40 maximum concentration of NDMA in potable reuse water is set at $10 \mathrm{ng} / \mathrm{L}$ by the Australian

41 Water Recycling Guideline. ${ }^{4}$ Unlike most high molecular weight or charged TOrCs, the rejection

42 of small and uncharged chemicals, particularly $N$-nitrosamines, by reverse osmosis (RO)

43 membranes varies widely and is often quite low. ${ }^{5-8}$ In particular, since NDMA has a low

44 molecular weight $(74 \mathrm{~g} / \mathrm{mol})$ and is uncharged in environmental water, NDMA rejection of less

45 than $50 \%$ has been reported for many RO membranes. ${ }^{9}$ NDMA concentrations in RO permeate

46 higher than the guideline value of $10 \mathrm{ng} / \mathrm{L}$ have often been routinely reported in full scale potable

47 water reuse schemes. ${ }^{7}, 10$ As a result, residual NDMA is further removed by advanced oxidation

48 process (AOP). ${ }^{11}$ In the multi-barrier approach, AOP is expected to act as a redundant treatment

49 barrier to degrade contaminants that have inadvertently passed through RO treatment. Thus,

50 reliable and adequate NDMA removal by RO is essential to ensure public health protection in

51 potable water reuse.

52 A recent study by Fujioka ${ }^{12}$ has demonstrated that high rejection of NDMA (e.g. $>92 \%$ ) can be

53 achieved by heat-treating RO membranes. However, economic feasibility of this approach has

54 not been ascertained especially, as NDMA rejection is coupled with a reduction in water 
55 permeability. The trade-off relationship is likely associated with reduction in free-volume hole56 size, which could limit the transport of both solute (i.e., NDMA) and water molecules. ${ }^{13}, 14$ 57 Nevertheless, the role of free-volume hole-size has not been fully understood from the viewpoint 58 of RO membrane properties due to analytical limitations at sub-nanometre scale. ${ }^{15}$ In addition to 59 size exclusion, intermolecular interactions between uncharged chemicals and the functional 60 groups of the polyamide skin layer can play a role in determining their transport through RO 61 membrane matrix. ${ }^{16-19} \mathrm{~N}$-nitrosamines, which bear high electronegativity atoms (i.e., nitrogen 62 and oxygen atoms), are polar chemicals with have high partial negative charges. There has been 63 some evidence from the literature that dipolar interaction (e.g. hydrogen bonding) between small 64 and uncharged organic molecules and the membrane polyamide skin layer may their partitioning 65 to and transport through the skin layer. ${ }^{18,20}$

66 New understanding of the interplay between size exclusion and intermolecular interaction in 67 governing the rejection of small and uncharged organic solutes has the potential to facilitate the 68 development of high NDMA rejection membranes. For example, the strong correlation between 69 minimum projection area and rejection confirms that the clearance between NDMA and the 70 membrane free-volume hole is an important parameter. As a result, membrane development may 71 focus on narrowing down the free-volume hole-diameter without considerably compromising 72 membrane permeability. Likewise, surface coating or modifying the membrane material 73 composition may also be explored to regulate intermolecular interaction, thus, enhancing the 74 rejection of NDMA as well as other small and uncharged organics of significant concern.

75 This study aimed to elucidate the influence of size exclusion and dipolar interactions on the 76 rejection of TOrCs including NDMA by polyamide-based RO membranes. Four $N$-nitrosamines, 77 including NDMA and NMEA, were used to demonstrate the importance of size exclusion. To 
78 identify the importance of dipolar interactions, four other chemicals similar to NDMA or NMEA

79 in structure but have less or no nitrogen atoms were used with two RO membranes that have

80 different nitrogen content on their surface.

\section{MATERIALS AND METHODS}

\section{Chemicals}

83 All chemicals used for separation experiments were analytical grade. The four $N$-nitrosamines in 84 this study - namely NDMA, NMEA, NPYR, and NMOR (Table 1) - were from Ultra 85 Scientific (Kingstown, RI, USA). In addition, chemicals with similar backbone structure to the 86 two smallest $N$-nitrosamines (i.e. NDMA and NMEA) in terms of molecular weight but are

87 different in the number of nitrogen atoms in the molecule were also selected. For comparison 88 with NDMA, the selected chemicals were dimethylformamide (DMF) and isobutyraldehyde 89 (IBAL), which have one and two nitrogen atoms less than that of the corresponding $\mathrm{N}$ 90 nitrosamine reference, respectively (Table 1). Likewise, for comparison with NMEA, the 91 selected chemicals were $N$-Ethyl- $N$-methylformamide (NEMF) and 2-methylbutanal (MBTL),

92 which have one and two nitrogen atoms less than that of the corresponding $N$-nitrosamine

93 reference, respectively. All of the eight solutes are hydrophilic and neutral (uncharged) at the 94 experimental $\mathrm{pH}$ (pH 6 to 7) of this study (Table S1). 
95 Table 1 - Structure and properties of the selected chemicals.

\begin{tabular}{|c|c|c|c|c|}
\hline Group & Number of nitrogen atom & 2 & 1 & 0 \\
\hline \multirow[t]{4}{*}{ A } & Name & NDMA & DMF & IBAL \\
\hline & Structure & & & \\
\hline & Molecular weight $[\mathrm{g} / \mathrm{mol}]$ & 74.1 & 73.1 & 72.1 \\
\hline & Minimum projection area $a^{\mathrm{a}, \mathrm{b}}\left[\AA^{2}\right]$ & 19.4 & 20.2 & 22.9 \\
\hline \multirow[t]{3}{*}{$\mathrm{B}$} & Name & NMEA & NEMF & MBTL \\
\hline & Molecular weight $[\mathrm{g} / \mathrm{mol}]$ & 88.1 & 87.1 & 86.1 \\
\hline & Minimum projection area ${ }^{\mathrm{a}, \mathrm{b}}\left[\AA^{2}\right]$ & 22.1 & 24.0 & 25.4 \\
\hline \multirow[t]{4}{*}{$\mathrm{C}$} & Name & NPYR & N.A. & N.A. \\
\hline & Structure & & & \\
\hline & Molecular weight $[\mathrm{g} / \mathrm{mol}]$ & 100.1 & & \\
\hline & Minimum projection area $a^{\mathrm{a}, \mathrm{b}}\left[\AA^{2}\right]$ & 24.1 & & \\
\hline \multirow[t]{3}{*}{$\mathrm{D}$} & Name & NMOR & N.A. & N.A. \\
\hline & Molecular weight $[\mathrm{g} / \mathrm{mol}]$ & 116.1 & & \\
\hline & Minimum projection area ${ }^{\mathrm{a}, \mathrm{b}}\left[\AA^{2}\right]$ & 26.9 & & \\
\hline
\end{tabular}

$96{ }^{a}$ Marvin software (ChemAxon, Budapest, Hungary).

$97{ }^{\mathrm{b}}$ Minimum projection area is the area of the compound projection with the minimum plane of its

98 circular disk, based on the van der Waals radius.

99 N.A.: Not available (not used).

\section{Membrane treatment system and protocols}

101 A pilot-scale cross-flow RO system with one 4-inch low pressure RO membrane element was

102 used (Fig. S1 and Text S1a). The RO membrane elements selected in this study were ESPA2-

103 LD-4040 and LFC3-LD-4040 (Hydranautics/Nitto, CA, USA), both of which have been widely

104 used for water recycling applications. Both RO membrane elements have a large membrane

105 surface area $\left(7.43 \mathrm{~m}^{2}\right.$ as opposed to $<0.01 \mathrm{~m}^{2}$ in a typical lab scale study), which eliminates any

106 local variation in separation performance. Conductivity rejection by the ESPA2-LD-4040 RO

107 membrane element is $98.5 \%$, slightly lower than that of the LFC3-LD-4040 RO element (98.9\%) 
108 (Table S2). The skin layer of polyamide ESPA2 RO membrane is formed via the cross-linking

109 of $m$-phenylenediamine and trimesoyl chloride monomers; thus, polyamide materials are present

110 in the top skin layer. ${ }^{21}$ LFC3 RO membrane is prepared by coating a layer of polyvinyl alcohol

111 (PVA, $\left.\left(\mathrm{C}_{2} \mathrm{H}_{4} \mathrm{O}\right)_{\mathrm{x}}\right)$ onto a ready-made ESPA2 RO membrane sheet; thus, a major difference

112 between LFC3 and ESPA2 RO membranes is the presence of the PVA active skin layer. These

113 two RO membranes were evaluated to examine the influence of nitrogen content in the

114 membrane polymeric matrix on the rejection of nitrogen bearing chemicals.

115 The RO system was operated in a recirculation mode at a constant permeate flux of $20 \mathrm{~L} / \mathrm{m}^{2} \mathrm{~h}$,

116 constant feed temperature of $20{ }^{\circ} \mathrm{C}$, and the system recovery of $20 \%$. Prior to each separation

117 experiment, the system was operated using a $50 \mathrm{~L}$ deionised water for at least one hour to

118 stabilise the filtration performance (Text S1b). Thereafter, stock solution of each chemical was

119 added to obtain $700 \mathrm{ng} / \mathrm{L}$ of each $N$-nitrosamine or $14-20 \mathrm{mg} / \mathrm{L}$ for the other chemicals in the

120 feed solution.

\section{Analysis}

122 Concentrations of four $N$-nitrosamines were determined by high-performance liquid

123 chromatography-photochemical reaction-chemiluminescence. ${ }^{22}$ Concentrations of DMF and

124 NEMF were determined through solid-phase extraction followed by gas chromatography (GC)

125 and mass spectrometry (MS). Concentrations of IBAL and MBTL were determined through 126 derivatisation followed by liquid phase extraction and GC-MS (Text S1c). Chemical 127 composition of the face side as well as the side facing the supporting layer (herein called reverse 128 side) of the skin layer was evaluated using an X-ray photoelectron spectroscopy (XPS) 129 (ESCA3200, Shimadzu, Tokyo, Japan) (Text S1d). 


\section{RESULTS AND DISCUSSION}

\section{Elemental composition of RO skin layer}

132 Three organic elements detected here include: oxygen $(\mathrm{O})$, nitrogen $(\mathrm{N})$, and carbon $(\mathrm{C})$ (Fig.

133 S2). The face side of ESPA2 RO membrane had the elemental composition of O (15\%), N (12\%),

134 and $\mathrm{C}(72 \%)$. The reverse side of ESPA2 membrane showed similar elemental composition at $\mathrm{O}$

135 (15\%), N (11\%), and C (74\%), which will be same for the reverse side of LFC3 membrane.

136 Almost identical elemental composition between the face side and reverse side indicate that the

137 intermolecular interaction occurs at similar levels during the transport of chemicals through the

138 skin layer. In contrast, the face side of LFC3 RO membrane had a low $\mathrm{N}$ content of only $6 \%$.

\section{Rejection of TOrCs}

140 The rejection of four $N$-nitrosamines by the ESPA2 RO membrane increased according to the

141 increase in their molecular weight (Fig. 1a). However, when other chemicals with similar

142 molecular structure but difference in the number of nitrogen atoms are also considered, the

143 correlation between rejection and molecular weight was no longer valid. The three chemicals in

144 group A (namely NDMA, DMF, and IBAL) have similar molecular weight (72-74 g/mol) and

145 structure (Table 1) but markedly different rejection (30, 52, and 88\%, respectively) (Fig. 1a).

146 Likewise, the three chemicals in group B (namely NMEA, NEMF, and MBTL) also have similar

147 molecular weight (86-88 $\mathrm{g} / \mathrm{mol})$ and structure (Table 1), yet their rejection also varied over a

148 wide range. Similarly, the rejection of the selected chemicals by LFC3 RO membrane was not 149 correlated with their molecular weight (Fig. 1b). 

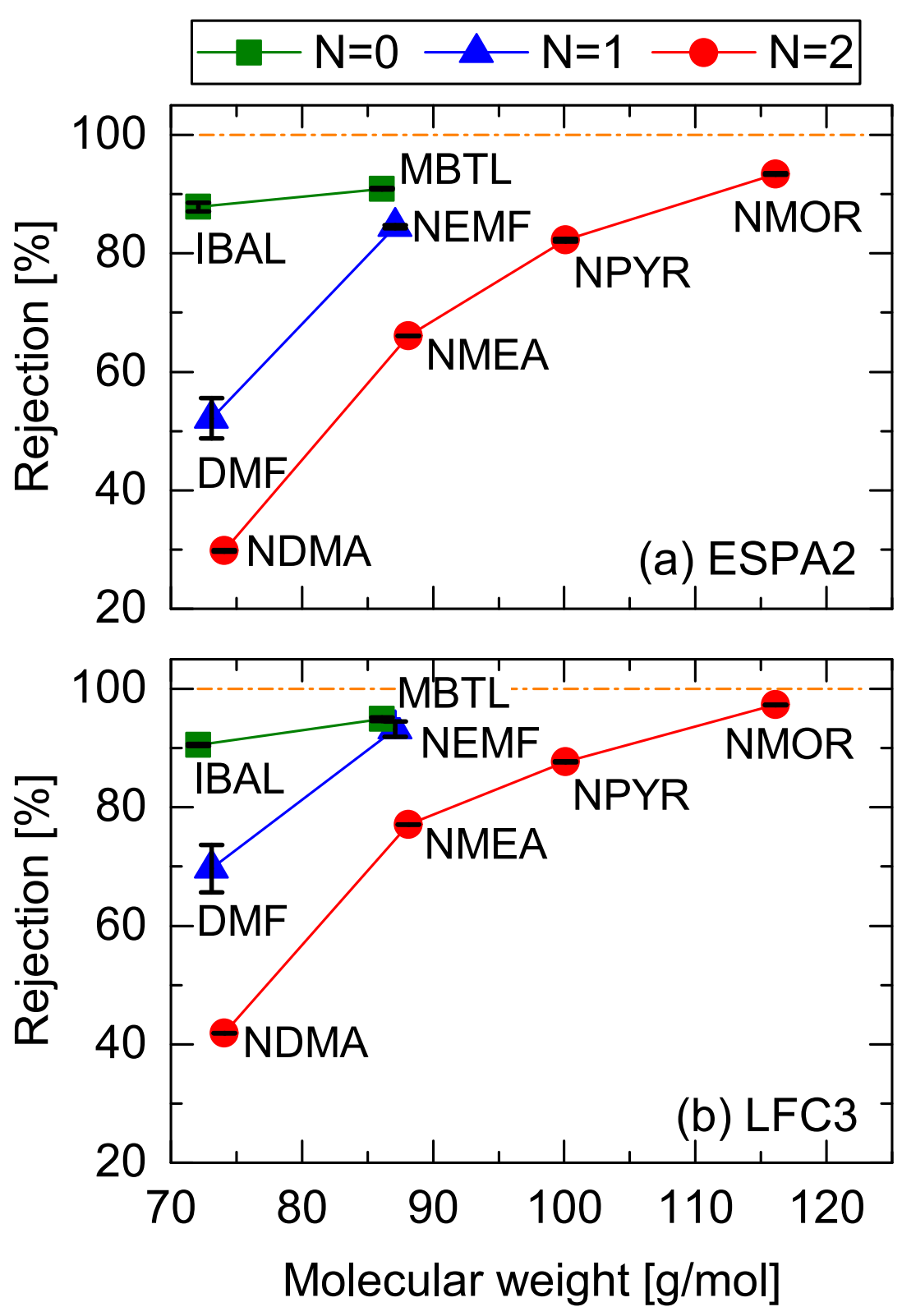

151 Fig. 1 - Rejection of the selected chemicals with and without nitrogen $(\mathrm{N})$ atoms in deionised 152 water by (a) ESPA2 and (b) LFC3 RO membranes as a function of molecular weight (Permeate 153 flux $=20 \mathrm{~L} / \mathrm{m}^{2} \mathrm{~h}$, feed temperature $=20{ }^{\circ} \mathrm{C}$, and transmembrane pressure $=0.41$ and $0.50 \mathrm{MPa}$ 154 for the ESPA2 and LFC3 RO membranes, respectively; error bars represent one standard 155 deviation of two replicate samples).

156 Further analysis indicated that the minimum projection area (MPA) of the selected chemicals

157 instead of molecular weight was better correlated with their rejections for both RO membranes

158 (Fig. 2). MPA represents the minimum projection cross-sectional area of a chemical (Fig. S3). 
160 S4), because of the basis similar to minimum projected area, which is based on the van der

161 Waals radius. In contrast, the molecular length of the selected chemicals did not correlate with

162 their rejections (Fig. S5). Results associated with MPA indicate that the 2-dimensional molecular

163 property can be a more relevant parameter that governs the rejection of small and uncharged

164 chemicals. In fact, a strong correlation between MPA and TOrCs has also been reported with

165 nanofiltration (NF) and cellulose triacetate RO membranes elsewhere. ${ }^{23,}{ }^{24}$ The transport of

166 TOrCs through RO membrane occurs via three major steps: (a) approach to the face side of the

167 membrane surface and penetration into the membrane structure; (b) diffuse through the skin

168 layer; and (c) exit from the membrane structure and departing from the reverse side to the

169 supporting layer. ${ }^{25}$ After sorption (or partitioning) of uncharged chemicals into the membrane

170 polymeric matrix, their diffusion can be influenced by the clearance between the chemical and

171 free-volume hole-size of the membrane active skin layer. 

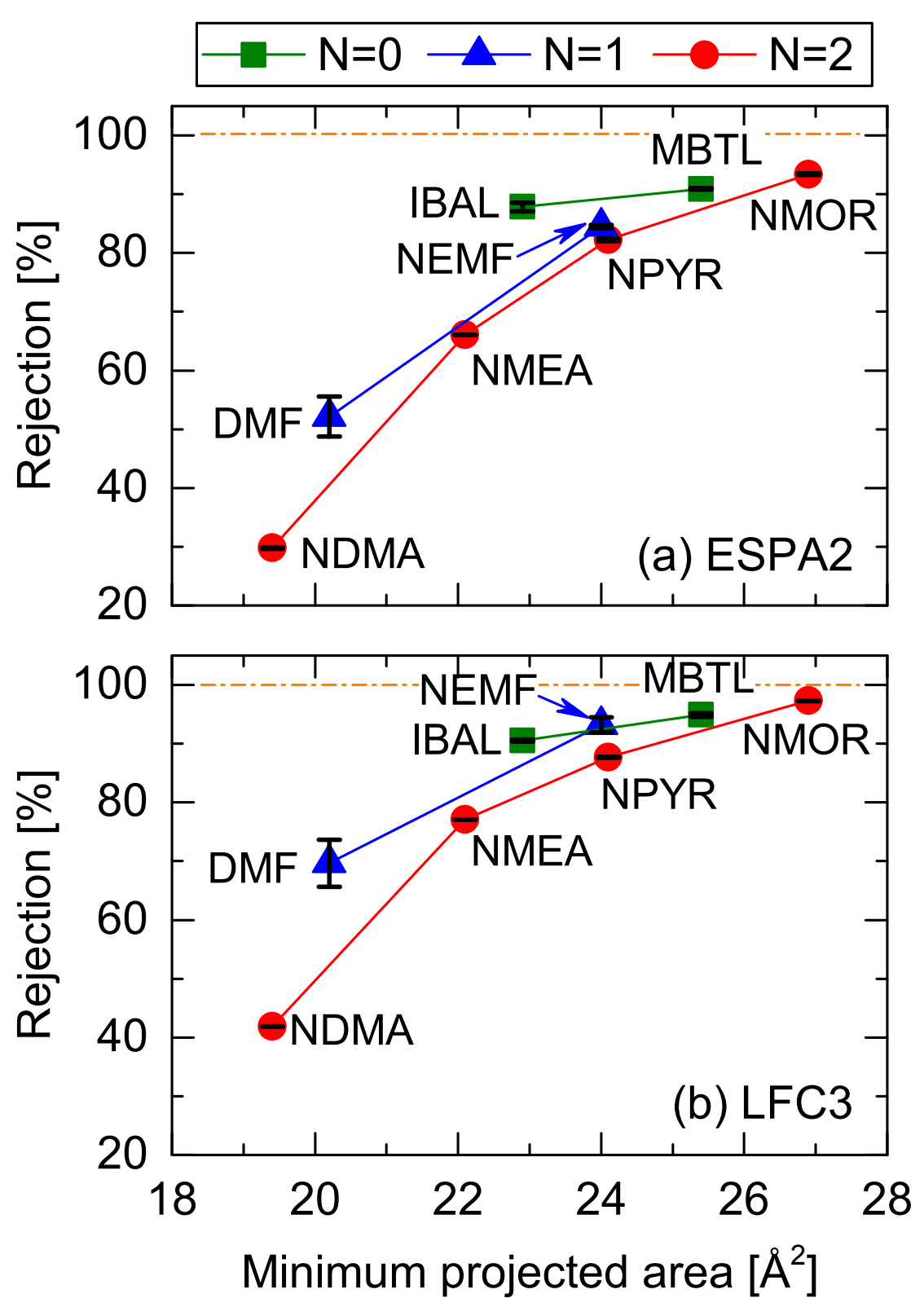

173 Fig. 2 - Rejection of the selected chemicals with and without nitrogen $(\mathrm{N})$ atoms in deionised 174 water by (a) ESPA2 and (b) LFC3 RO membranes as a function of MPA (Permeate flux $=20$ $175 \mathrm{~L} / \mathrm{m}^{2} \mathrm{~h}$ and feed temperature $=20^{\circ} \mathrm{C}$; error bars represent one standard deviation of two replicate 176 samples).

177 Assuming that the chemical can rotate at any directions, the minimum clearance is attained with 178 two dimensional area (e.g. MPA), which can determine whether the chemical passes through the 179 free-volume hole. MPA of NDMA (MPA $\left.=19 \AA^{2}\right)$ and other selected chemicals $\left(20-27 \AA^{2}\right)$ was 
180 comparable to the mean cross-sectional area of free-volume holes of ESPA2 RO membrane (24

$181 \AA^{2}$ ), which was determined by approximating free-volume holes as uniform sphere-like voids

182 using positron annihilation technique. ${ }^{21}$ The clearance between solute dimensions and membrane

183 free-volume holes can govern the transport of chemicals not only during the entry to the

184 membrane matrix but also during their diffusion through the skin layer, because free-volume

185 holes are composed small network and large aggregate holes that are more likely to provide

186 hinder solute transport depending on the level of clearance. ${ }^{26,27}$ This clearance may explain the

187 overall trend of high rejections by LFC3 RO membrane; free-volume hole-size in the membrane

188 matrix could have been reduced by the coating process compared to that of the ESPA2 RO

189 membrane.

190 It is noted that the rejection of chemicals with one or no nitrogen atoms in structure by ESPA2

191 RO membrane was generally higher than their corresponding $N$-nitrosamines $(\mathrm{N}=2)$ (Fig. 2a).

192 Hydrogen bonding between these nitrogen bearing chemicals and functional groups of

193 polyamide membrane can be the cause of this observed variation. In the polyamide skin layer,

194 hydrogen atom on the amide $(\mathrm{CO}-\mathrm{NH}-)$ or free amine $\left(\mathrm{NH}_{2}^{-}\right)$functional groups can act as a

195 hydrogen bond donor, because $\mathrm{N}$ in the amide or amine functional group strips electron density

196 from the proton, which causes its partial positive charge $\left(\delta^{+}\right)$(Fig. S6). Although keto group

$197(=\mathrm{O})$ in all of the chemicals is a hydrogen bond acceptor with partial negative charge $\left(\delta^{-}\right)$,

198 nitrogen atoms in nitrogen bearing chemicals (e.g., NDMA) are also hydrogen bond acceptors,

199 which increases the number of hydrogen bonding pairs. In contrast, both IBAL and MBTL do

200 not have any nitrogen atom in their molecular structure; thus, the number of hydrogen bonding

201 pair is less than NDMA and NMEA. The increased number of hydrogen bonds may enhance the

202 diffusion of nitrogen bearing chemicals, enhancing their permeation to the permeate. 
203 A similar trend but with discernible difference in individual rejection values between $\mathrm{N}$ 204 nitrosamines and other chemicals with less nitrogen atoms was also observed for the LFC3 RO 205 membrane (Fig. 2b). The LFC3 RO membrane has a lower nitrogen content on the face side due 206 to the PVA coating layer (Table S1) comparing to the ESPA2. However, hydroxyl groups (-OH) 207 of the PVA layer can also act as a hydrogen bond donor and form hydrogen bonding with N208 bearing chemicals. Indeed, the hydrogen bond donating potential of the hydroxyl group is higher 209 than that of the amide group of the original polyamide layer (Fig. S6). Thus, hydrogen bonding 210 between the selected chemicals and PVA layer can be stronger than that between the chemicals 211 and polyamide chains. This implies that two nitrogen bearing chemicals that have two hydrogen 212 acceptor sites (i.e., $N$-nitrosamines) can have more hydrogen bonding with the PVA layer (i.e.

213 LFC3 membrane), causing the discrepancy in their rejection trend with one or no nitrogen 214 bearing chemicals (one hydrogen acceptor site) (Fig. 2b). These results in this study suggest 215 hydrogen bonding as a potential cause of the low rejection of nitrogen bearing chemicals 216 including $N$-nitrosamines. It is noted that the tests in this study were conducted using deionised 217 water, whereas in water recycling the rejection of these chemicals may vary due to the presence 218 of dissolved ions and hydrogen bond disruptors such as urea. To confirm the importance of 219 hydrogen bonding, further investigation with many other chemicals with different partial positive 220 or negative charges and different water matrix is necessary.

\section{Implications for future $\mathbf{R O}$ membranes}

222 This study showed MPA is a more appropriate parameter than molecular weight for describing 223 the rejection of small and uncharged chemicals. In addition, this study identified for the first time 224 that the permeation of nitrogen atom-containing chemicals through polyamide RO membrane

225 can be enhanced by the number of hydrogen bond pairs. Based on the importance in size 
226 exclusion mechanisms identified in this study, the restriction of free-volume hole-size can

227 primarily reduce the number of NDMA molecules entering the free-volume holes, enhancing

228 NDMA rejection. However, free-volume hole-size restriction can also inhibit the entry of water

229 molecules, consequently reducing water permeability. The effect of hydrogen bonding identified

230 in this study suggests that the reduction of electron donor in RO membrane matrix has the

231 potential to reduce the permeation of NDMA molecules. Hydrogen bond donor can be removed

232 or reduced by changing membrane polymer materials, however, the change in polymer materials

233 can also change the membrane structure including free-volume hole-size. Provision of surface

234 coating layer without hydrogen bonding donor also has the potential of enhanced NDMA

235 rejection.

\section{SUPPORTING INFORMATION}

237 Additional text, tables and figures.

\section{ACKNOWLEDGEMENT}

239 This work was supported by JSPS KAKENHI Grant Number JP18H01572. We also thank

240 Hydranautics/Nitto for providing RO membrane samples for this investigation.

\section{REFERENCES}

242 1. Krasner, S. W.; Mitch, W. A.; McCurry, D. L.; Hanigan, D.; Westerhoff, P., Formation, 243 Precursors, Control, and Occurrence of Nitrosamines in Drinking Water: A Review. Water Res. 244 2013, 47, (13), 4433-4450, Doi:10.1016/j.watres.2013.04.050.

245 2. Sgroi, M.; Vagliasindi, F. G. A.; Snyder, S. A.; Roccaro, P., N-Nitrosodimethylamine 246 (Ndma) and Its Precursors in Water and Wastewater: A Review on Formation and Removal. 247 Chemosphere 2018, 191, (Supplement C), 685-703, Doi:10.1016/j.chemosphere.2017.10.089. 
3. Shah, A. D.; Mitch, W. A., Halonitroalkanes, Halonitriles, Haloamides, and NNitrosamines: A Critical Review of Nitrogenous Disinfection Byproduct Formation Pathways. Environ. Sci. Technol. 2012, 46, (1), 119-131, Doi:10.1021/es203312s.

4. NRMMC; EPHC; AHMC, Australian Guidelines for Water Recycling: Managing Health and Environmental Risks (Phase 2): Augmentation of Drinking Water Supplies. Environment Protection and Heritage Council, National Health and Medical Research Council, Natural Resource Management Ministerial Council: Canberra, 2008.

5. $\quad$ Farré, M. J.; Döderer, K.; Hearn, L.; Poussade, Y.; Keller, J.; Gernjak, W., Understanding the Operational Parameters Affecting Ndma Formation at Advanced Water Treatment Plants. $J$. Hazard. Mater. 2011, 185, (2-3), 1575-1581, Doi:10.1016/j.jhazmat.2010.10.090.

6. Bellona, C.; Drewes, J. E.; Oelker, G.; Luna, J.; Filteau, G.; Amy, G., Comparing Nanofiltration and Reverse Osmosis for Drinking Water Augmentation. J. AWWA 2008, 100, (9), 102-116, Doi:10.1002/j.1551-8833.2008.tb09724.x.

261 7. Fujioka, T.; Khan, S. J.; McDonald, J. A.; Roux, A.; Poussade, Y.; Drewes, J. E.; Nghiem, 262 L. D., $N$-Nitrosamine Rejection by Reverse Osmosis Membranes: A Full-Scale Study. Water Res. 2013, 47, (16), 6141-6148, Doi:10.1016/j.watres.2013.07.035.

8. Plumlee, M. H.; López-Mesas, M.; Heidlberger, A.; Ishida, K. P.; Reinhard, M., NNitrosodimethylamine (Ndma) Removal by Reverse Osmosis and Uv Treatment and Analysis Via Lc-Ms/Ms. Water Res. 2008, 42, (1-2), 347-355, Doi:10.1016/j.watres.2007.07.022.

9. $\quad$ Tu, K. L.; Fujioka, T.; Khan, S. J.; Poussade, Y.; Roux, A.; Drewes, J. E.; Chivas, A. R.; 268 Nghiem, L. D., Boron as a Surrogate for N-Nitrosodimethylamine Rejection by Reverse Osmosis Membranes in Potable Water Reuse Applications. Environ. Sci. Technol. 2013, 47, (12), 64256430, Doi:10.1021/es400732x.

10. Fujioka, T.; Khan, S. J.; Poussade, Y.; Drewes, J. E.; Nghiem, L. D., N-Nitrosamine Removal by Reverse Osmosis for Indirect Potable Water Reuse - a Critical Review Based on Observations from Laboratory-, Pilot- and Full-Scale Studies. Sep. Purif. Technol. 2012, 98, 503-515, Doi:10.1016/j.seppur.2012.07.025.

11. Leverenz, H. L.; Tchobanoglous, G.; Asano, T., Direct Potable Reuse: A Future Imperative. J. Water Reuse Desalination 2011, 1, (1), 2-10, Doi:10.2166/wrd.2011.000.

280 13. Geise, G. M.; Park, H. B.; Sagle, A. C.; Freeman, B. D.; McGrath, J. E., Water 281 Permeability and Water/Salt Selectivity Tradeoff in Polymers for Desalination. J. Membr. Sci. 282 2011, 369, (1-2), 130-138, Doi:10.1016/j.memsci.2010.11.054. 
14. Ju, H.; Sagle, A. C.; Freeman, B. D.; Mardel, J. I.; Hill, A. J., Characterization of Sodium Chloride and Water Transport in Crosslinked Poly(Ethylene Oxide) Hydrogels. J. Membr. Sci. 2010, 358, (1-2), 131-141, Doi:10.1016/j.memsci.2010.04.035.

15. Fujioka, T.; Oshima, N.; Suzuki, R.; Khan, S. J.; Roux, A.; Poussade, Y.; Drewes, J. E.; Nghiem, L. D., Rejection of Small and Uncharged Chemicals of Emerging Concern by Reverse Osmosis Membranes: The Role of Free Volume Space within the Active Skin Layer. Sep. Purif. Technol. 2013, 116, 426-432, Doi:10.1016/j.seppur.2013.06.015.

16. Dražević, E.; Košutić, K.; Kolev, V.; Freger, V., Does Hindered Transport Theory Apply

to Desalination Membranes? Environ. Sci. Technol. 2014, 48, (19), 11471-11478, Doi:10.1021/es502085p.

293 17. Freger, V., Outperforming Nature's Membranes. Science 2015, 348, (6241), 1317-1318, Doi:10.1126/science.aab3727.

18. Nghiem, L. D.; Schäfer, A. I.; Elimelech, M., Removal of Natural Hormones by Nanofiltration Membranes: Measurement, Modeling, and Mechanisms. Environ. Sci. Technol. 2004, 38, (6), 1888-1896, Doi:10.1021/es034952r.

19. Bellona, C.; Drewes, J. E.; Xu, P.; Amy, G., Factors Affecting the Rejection of Organic

Solutes During Nf/Ro Treatment - a Literature Review. Water Res. 2004, 38, (12), 2795-2809, Doi:10.1016/j.watres.2004.03.034.

20. Ben-David, A.; Bernstein, R.; Oren, Y.; Belfer, S.; Dosoretz, C.; Freger, V., Facile Surface Modification of Nanofiltration Membranes to Target the Removal of EndocrineDisrupting Compounds. J. Membr. Sci. 2010, 357, (1), 152-159, Doi:10.1016/j.memsci.2010.04.015.

21. Fujioka, T.; O'Rourke, B. E.; Michishio, K.; Kobayashi, Y.; Oshima, N.; Kodamatani, H.; Shintani, T.; Nghiem, L. D., Transport of Small and Neutral Solutes through Reverse Osmosis Membranes: Role of Skin Layer Conformation of the Polyamide Film. J. Membr. Sci. 2018, 554, 301-308, Doi:10.1016/j.memsci.2018.02.069.

22. Kodamatani, H.; Roback, S. L.; Plumlee, M. H.; Ishida, K. P.; Masunaga, H.; Maruyama, N.; Fujioka, T., An Inline Ion-Exchange System in a Chemiluminescence-Based Analyzer for Direct Analysis of N-Nitrosamines in Treated Wastewater. J. Chromatogr. A 2018, 1553, 51-56, Doi:10.1016/j.chroma.2018.04.030.

23. Fujioka, T.; Khan, S. J.; McDonald, J. A.; Nghiem, L. D., Rejection of Trace Organic Chemicals by a Hollow Fibre Cellulose Triacetate Reverse Osmosis Membrane. Desalination 2015, 368, 69-75, Doi:10.1016/j.desal.2014.06.011.

24. Fujioka, T.; Khan, S. J.; McDonald, J. A.; Nghiem, L. D., Nanofiltration of Trace Organic Chemicals: A Comparison between Ceramic and Polymeric Membranes. Sep. Purif. Technol. 2014, 136, 258-264, Doi:10.1016/j.seppur.2014.08.039. 
319 25. Geise, G. M.; Paul, D. R.; Freeman, B. D., Fundamental Water and Salt Transport 320 Properties of Polymeric Materials. Prog. Polym. Sci. 2014, 39, (1), 1-42, 321 Doi:10.1016/j.progpolymsci.2013.07.001.

322 26. Kolev, V.; Freger, V., Hydration, Porosity and Water Dynamics in the Polyamide Layer 323 Of reverse Osmosis Membranes: A Molecular Dynamics Study. Polymer 2014, 55, (6), 1420324 1426, Doi:10.1016/j.polymer.2013.12.045.

325 27. Kolev, V.; Freger, V., Molecular Dynamics Investigation of Ion Sorption and Permeation 326 in Desalination Membranes. J. Phys. Chem. B 2015, 119, (44), 14168-14179, 327 Doi:10.1021/acs.jpcb.5b06566. 
330 TOC

Decreasing number of $\mathrm{N}$ atom in the molecule

331 Increasing rejection due to intermolecular interaction

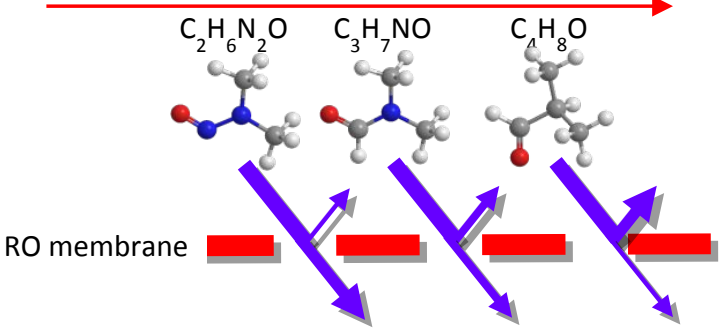

